\title{
Estudo de aspectos adaptativos e psicológicos de mães de crianças acolhidas em abrigos
}

\author{
Study of psychological and adaptive aspects of mothers of children in shelters
}

Nirã dos Santos Valentim ${ }^{[a]}$, Kayoko Yamamoto ${ }^{[b]}$

[a] [Mestre em Psicologia Clínica, docente das Faculdades Integradas de Santo André, Santo André, SP - Brasil, e-mail: niravalentim@usp.br

${ }^{[b]}$ Doutora em Psicologia Clínica, docente do Programa de Pós-Graduação em Psicologia da Universidade de São Paulo São Paulo, SP - Brasil, e-mail: kayamato@terra.com.br

Recebido: 29/08/2011 Received: 08/29/2011

Aprovado: 05/06/2012 Approved: 06/05/2012

\section{Resumo}

0 acolhimento de crianças em abrigos mostra uma realidade de violência intrafamiliar, negligência e abandono parental. Interessada na compreensão desse tema, a presente pesquisa teve por objetivo geral delinear os aspectos adaptativos e psicológicos de mães de crianças abrigadas. Participaram deste estudo sete mães, cujos filhos com idade entre 0 a 10 anos e 11 meses estavam acolhidos e recebiam visitas regulares delas. Os instrumentos utilizados foram: entrevista preventiva; Escala Diagnóstica Adaptativa Operacionalizada (EDAO) e Teste do Desenho da Figura Humana. Os resultados obtidos com a Escala Diagnóstica Adaptativa Operacionalizada (EDAO) revelaram: três mães com adaptação ineficaz grave; três mães com adaptação ineficaz severa; e uma mãe com adaptação ineficaz moderada. Os setores afetivo-relacionais, a produtividade e o aspecto sociocultural mostraram-se mais comprometidos. Revelaram ainda a transmissão transgeracional da violência e do abandono vivenciados pelas mães na própria infância e o empobrecimento do papel materno. No Teste do Desenho da Figura Humana, predominaram o autoconceito e a autoimagem acentuadamente negativos. Verificou-se, assim, que os fatores psicológicos e adaptativos evidenciados na pesquisa apresentavam forte associação com o abrigamento dos filhos.

Palavras-chave: Crianças institucionalizadas; mães; Escala Diagnóstica Adaptativa Operacionalizada; desenho de figuras humanas.

\section{Abstract}

Children in shelter homes display a reality of interfamily violence, negligence and parental abandonment. Interested in understanding this subject, this research had the aim to investigate adaptive and psychological aspects of mothers of sheltered children. Seven mothers participated in this study, whose children are aged between 0 to 10 years and 11 months, and were in shelter and received regular visits. The instruments used were: preventive interview; Operational Adaptive Diagnostic Scale (EDAO) e Human Figure Drawing Test. The results achieved by the usage of Operational Adaptive Diagnostic Scale (EDAO) presented 3 mothers with serious ineffective adaptation; 3 mothers with severe ineffective adaptation; and 1 mother with moderate ineffective adaptation. Affective-relational sectors, productivity and socio-cultural aspect were even compromised. It was observed the transgenerational transmission of violence and abandonment 
suffered by mothers in their childhood, in addition of a decline of the maternal function. In Humans Figures Drawing, very negative self concept and self image were predominant. Adaptive and psychological factors of mothers were strongly correlated with sheltered children.

Keywords: Institutionalized children. Mothers. Operational Adaptive Diagnostic Scale. Humans Figures Drawing.

\section{Introdução}

O abrigo, previsto e descrito no Estatuto da Criança e do Adolescente, (Brasil, 1990) que o fundamenta, é considerado medida de proteção para crianças e adolescentes que estejam em situação de risco em suas famílias. Os Conselhos Tutelares e as Varas da Infância e Adolescência encaminham as crianças vítimas de abandono, violência doméstica e sexual, negligência e carência de recursos materiais para o acolhimento em abrigos, instituições cuja função é amparar e oferecer os cuidados básicos que essas crianças necessitam, enquanto seus pais ou familiares se mostram incapazes de exercer o papel de protetor/provedor.

0 acolhimento deve ter, porém, caráter provisório, visando à preservação dos vínculos familiares notadamente entre pais e filhos -, com a preocupação de promover, em tempo mais breve possível, a reinserção das crianças e adolescentes no convívio familiar (Silva, 2004). Essa intenção, no entanto, é dificultada pela escassez de políticas públicas que poderiam facilitar os abrigos no auxílio às dificuldades sociais, econômicas e psicológicas das famílias, bem como a composição de equipes de profissionais especializados para o atendimento a essas demandas específicas.

\section{0 papel da parentalidade}

Estudos sobre o papel materno e as causas do abandono e da negligência em relação a crianças por suas mães, mostram alguns fatores para compreensão dessa situação. Entre outros, a miséria, a falta de recursos financeiros de mães que não têm o apoio do parceiro e da família, a exclusão social e abandono dessas mães pela sociedade e pelas políticas públicas. Apontam, ainda, para o fato de que as mães que foram abandonadas ou negligenciadas na infância repetem o abandono e apresentam dificuldades em assumir o papel materno com seus próprios filhos. Conteúdos de distanciamento afetivo, falta de sentimentos positivos dos pais e agressividade como forma de punição foram encontrados na infância dessas mulheres (Soejima \& Weber, 2008).

Dados sobre a transmissão transgeracional mostram que mulheres vítimas de violência na infância são mais suscetíveis à submissão à agressão de seus parceiros na vida adulta, assim como pode ser fator desencadeador o uso de álcool e outras drogas, colocando-a em risco para ser vítima, ou praticar violência (Silva, Falbo Neto \& Cabral Filho, 2009).

Nesse contexto há uma realidade de mulheres de baixa renda que chefiam suas famílias, com parceiros transitórios, que não contribuem com o sustento, ou com os cuidados dos filhos. Mostram-se solitárias, moram com seus filhos e geralmente com a família de origem, desempregadas e com dificuldades de reinserção no mercado de trabalho, devido à baixa escolaridade e à presença de doenças incapacitantes (Miguez-Naiff \& Sá, 2007).

Sendo assim, as mães cometem abusos com mais frequência, sendo a pobreza, a baixa escolaridade e a agressão sofrida quando crianças fatores de risco para o desenvolvimento da violência nestas famílias. A violência pode ser considerada por essas famílias como uma estratégia para solução de conflitos familiares (Weber, Viezzer, Branderburg \& Zocche, 2002; Dixon, Browne \& Hamilton-Giachritsis, 2009).

Tendo em vista o que foi acima mencionado, este estudo priorizou compreender os fatores adaptativos e psicológicos de mães de crianças acolhidas em abrigos, como um aspecto importante e fundamental para a compreensão do abandono e da negligência praticados pela figura parental contra os filhos - uma compreensão que poderia auxiliar os profissionais de diferentes especialidades que trabalham com essa demanda tão delicada a encontrar intervenções preventivas adequadas nos níveis primário, secundário e terciário (Leavel \& Clark, 1965).

\section{Método}

Esse estudo utilizou-se do método clínico-qualitativo de acordo com Turato (2008). 
A pesquisa foi aprovada pelo Comitê de Ética em Pesquisa com Seres Humanos do Instituto de Psicologia da USP (CEPH-IP) sob o ํㅜ 2007.004.

\section{Participantes}

A inclusão das mães como participantes desta pesquisa atendeu aos seguintes critérios: que não tivessem sido destituídas do poder familiar; que realizassem visitas regulares aos filhos nos abrigos e que os filhos tivessem idade de 0 a 10 anos e 11 meses, não tendo ingressado na adolescência, fator que poderia modificar a compreensão sobre os motivos do acolhimento, relacionados a dificuldades de relacionamento com os filhos devido a questões de não aceitação de limites, confrontos de autoridade, busca de independência, entre outros considerados mais comuns a essa faixa etária.

As mães foram convidadas a participar do estudo nos dias de visitas ao abrigo. Na ocasião, foram feitos esclarecimentos a respeito do objetivo do estudo e dos procedimentos a serem adotados. Obtida sua concordância, foi solicitada a assinatura do Termo de Consentimento Livre e Esclarecido (TCLE).

\section{Instrumentos}

Os instrumentos utilizados foram:

- Entrevista Preventiva que, segundo Simon (1995), é a entrevista utilizada quando o indivíduo não procura espontaneamente a entrevista psicológica, mas é convidado a participar pelo pesquisador ou preventivista, podendo ou não apresentar uma queixa específica;

- Escala Diagnóstica Adaptativa Operacionalizada EDAO para avaliar a eficácia da adaptação do indivíduo em relação a si mesmo e ao ambiente em que vive a partir das soluções que adota para atender suas necessidades nos quatro setores adaptativos: afetivo relacional, produtividade, sociocultural e orgânico (Simon, 1989);

- Teste do Desenho da Figura Humana (DFH) de Machover (1949) que tem o objetivo de conhecer a autoimagem e o autoconceito que cada indivíduo faz de si a partir da autoimagem projetada no desenho. A avaliação do teste foi realizada pela análise de desenhos de Van Kolck (1984), que adaptou a avaliação dos desenhos de Machover (1949) para a realidade brasileira.

\section{Procedimento}

Inicialmente, para obter autorização, 10 abrigos, como representantes legais das crianças sob sua responsabilidade, foram contatados. Destes, apenas 3 autorizaram a realização da pesquisa dentro de suas instalações. Sete foi o número de mães que preenchiam os critérios de inclusão na pesquisa. 0 nome de cada uma delas foi previamente informado à pesquisadora pela assistente social ou psicóloga dos abrigos para que a pesquisadora, no horário em que elas compareciam para visitar seus filhos, pudesse convidá-las a participar da pesquisa, esclarecendo devidamente o objetivo da pesquisa e do procedimento a ser adotado.

Ao final das entrevistas e da aplicação dos instrumentos, as mães, de acordo com as necessidades apresentadas, receberam um retorno a respeito de suas condições adaptativas e psicológicas, bem como orientações e encaminhamentos específicos considerados necessários.

\section{Resultados}

\section{Dados gerais da entrevista}

A Tabela 1 mostra que todas as mães estudadas estavam na idade adulta, havendo disparidade na escolaridade. Cinco mães eram alfabetizadas e duas mães não o eram - Maria era semianalfabeta e Ana era analfabeta. Esse dado parece indicar que não há relação aparente entre a baixa escolaridade das mães e o número de filhos.

Tabela 1 - Dados de identificação das mães

\begin{tabular}{|c|c|c|c|c|c|}
\hline Mães & Idade & $\begin{array}{l}\text { Escola- } \\
\text { ridade }\end{array}$ & $\begin{array}{l}\text { Tra- } \\
\text { balho }\end{array}$ & Filhos & $\begin{array}{l}\text { Aco- } \\
\text { lhidos }\end{array}$ \\
\hline Cibele & 29 anos & 8aㅗ série & Não & 3 & 3 \\
\hline Rosa & 40 anos & $5^{\underline{a}}$ série & Não & 5 & 2 \\
\hline Eva & 49 anos & $4^{\underline{a}}$ série & Não & 5 & 3 \\
\hline Berenice & 44 anos & $8^{\mathrm{a}}$ série & Não & 4 & 2 \\
\hline Maria & 26 anos & $2^{\mathrm{a}}$ série & Sim & 3 & 3 \\
\hline Ana & 41 anos & $1^{\mathrm{a}}$ série & Não & 2 & 2 \\
\hline Dirce & 34 anos & $8^{a}$ série & Sim & 5 & 4 \\
\hline
\end{tabular}


Quanto ao setor da produtividade, apenas Maria e Dirce relataram trabalhar fora de casa. Maria relatou um subemprego que não lhe permitia sustentar a si mesma e as filhas. Já Dirce relatou um trabalho com o qual mantinha a si e os filhos - quando eles moravam com ela - e ainda auxiliava a mãe nas despesas da casa. Eva relatou frequentar uma instituição, na qual realizava trabalhos manuais e conseguia vender alguns desses trabalhos; no entanto, isso não era suficiente para sua subsistência e relatou estar procurando um trabalho. Cibele mantinha-se com a pensão da filha mais velha, assim como Berenice, que se mantinha com a pensão do segundo filho. Rosa não relatou nenhuma fonte de renda e Ana tinha a subsistência garantida no abrigo em que morava.

Quanto ao acolhimento Cibele tinha os três filhos acolhidos; Rosa, dois filhos acolhidos, dois filhos adolescentes morando com ela (ambos já haviam sido acolhidos) e uma filha mais velha morando com sua mãe; Eva, quatro filhos acolhidos e uma filha morando com um ex-companheiro; Berenice, dois filhos menores acolhidos e dois filhos maiores de idade morando com ela (ambos haviam sido acolhidos na infância e retornaram para casa na maioridade); Maria, três filhas acolhidas; Ana, dois filhos acolhidos; e Dirce, quatro filhos acolhidos e um filho maior de idade que morava com sua mãe.

\section{Classificação Adaptativa}

A adequação setorial mostrou que, entre as 7 mães pesquisadas, todas apresentaram soluções pouquíssimo adequadas para o setor afetivo relacional (A-R). No setor produtividade (Pr), a adequação foi diferenciada: Cibele, Rosa e Berenice mostraram soluções pouquíssimo adequadas, o que resultou na classificação de adaptação ineficaz grave - grupo 5; Rosa, Maria e Ana, com as soluções pouco adequadas, foram classificadas como em estado de adaptação ineficaz severa - grupo 4; e Dirce, a única com respostas adequadas, foi classificada com adaptação ineficaz moderada - grupo 3 (Simon, 1989; 2005).

Dessa forma, seis mães encontravam-se diagnosticadas no Quadro Grave (qg) e apenas uma no Quadro Mediano (qm) (Simon, 1999).

Nos demais setores adaptativos - Orgânico (Or) e Sociocultural (S-C) -, avaliados qualitativamente (Simon, 1996), Cibele, Eva, Ana e Dirce mostraram soluções adequadas similares no setor Or e pouco adequadas no setor S-C; Berenice e Maria soluções pouco adequadas nos dois setores; e Rosa revelou soluções pouquíssimo adequadas no setor Or e pouco adequadas no setor S-C.

Tabela 2 - Diagnóstico adaptativo

\begin{tabular}{|c|c|c|c|c|}
\hline \multirow{2}{*}{ Mães } & \multicolumn{2}{|c|}{ Avaliação Setorial } & \multirow{2}{*}{$\begin{array}{l}\text { Classifica- } \\
\text { ção Adap- } \\
\text { tativa }\end{array}$} & \multirow{2}{*}{$\begin{array}{l}\text { Grupo } \\
\text { Adap- } \\
\text { tativo }\end{array}$} \\
\hline & A-R / Pr & Or / S-C & & \\
\hline Cibele & $\mathrm{PqA} / \mathrm{PqA}$ & Ad / PA & $\begin{array}{l}\text { Ineficaz } \\
\text { Grave }\end{array}$ & 5 \\
\hline Rosa & $\mathrm{PqA} / \mathrm{PqA}$ & $\mathrm{PqA} / \mathrm{PA}$ & $\begin{array}{l}\text { Ineficaz } \\
\text { Grave }\end{array}$ & 5 \\
\hline Eva & $\mathrm{PqA} / \mathrm{PA}$ & $\mathrm{Ad} / \mathrm{PA}$ & $\begin{array}{l}\text { Ineficaz } \\
\text { Severa }\end{array}$ & 4 \\
\hline Berenice & $\mathrm{PqA} / \mathrm{PqA}$ & $\mathrm{PA} / \mathrm{PA}$ & $\begin{array}{l}\text { Ineficaz } \\
\text { Grave }\end{array}$ & 5 \\
\hline Maria & $\mathrm{PqA} / \mathrm{PA}$ & $\mathrm{PA} / \mathrm{PA}$ & $\begin{array}{l}\text { Ineficaz } \\
\text { Severa }\end{array}$ & 4 \\
\hline Ana & $\mathrm{PqA} / \mathrm{PA}$ & Ad / PA & $\begin{array}{l}\text { Ineficaz } \\
\text { Severa }\end{array}$ & 4 \\
\hline Dirce & $\mathrm{PqA} / \mathrm{Ad}$ & Ad / PA & $\begin{array}{l}\text { Ineficaz } \\
\text { Moderada }\end{array}$ & 3 \\
\hline
\end{tabular}

Legenda: Ad - adequado; PA - pouco adequado; PqA - pouquíssimo adequado.

\section{Dados obtidos no DFH}

Os dados obtidos com o DFH mostraram que, em todas as mães, o autoconceito e a autoimagem encontravam-se preponderantemente negativos. $\mathrm{E}$ ainda existiam sentimentos de insegurança, inferioridade, inadequação, ansiedade, agressividade/ hostilidade, impulsividade, dependência emocional e regressão.

\section{Discussĩo}

\section{Delineamento adaptativo/psicológico}

A inadequação e os conflitos intra e extrapsíquicos no setor afetivo-relacional apareceram em todas as mães. 
Analisando as histórias relatadas por elas, pode-se observar, de um lado, uma realidade social que reflete a falta de recursos materiais, o desemprego, o abandono dos parceiros como verificado por Soejima e Weber (2008); e, de outro, significações pessoais que essas mães fazem da realidade objetiva que revelam um mundo de fantasias e idealizações, principalmente, das figuras masculinas, tornando difícil delimitar o quanto de realidade psíquica e de realidade objetiva estão envolvidas nas situações-problema vivenciadas (Simon, 2005).

0 envolvimento impulsivo com vários parceiros, vinculando-se rapidamente com quem lhes desse a mínima atenção, na expectativa ilusória de receber deles segurança e proteção - casa e sustento -, apareceu repetidamente nos relatos de Cibele, Rosa, Berenice e Maria. Com Berenice, Cibele e Maria, além de relacionamentos rápidos também envolveram-se em uma gravidez não planejada.

Nos relatos de Eva, Dirce e Ana, a busca por relacionamentos idealizados, e, por isso, inadequados e frustrantes também se fez presente; embora, com essas mães, os relacionamentos tenham se revelado mais duradouros do que com as demais mães. Por exemplo, Eva e Ana tiveram parceiros alcoólicos e agressivos que, em um primeiro momento, foram percebidos como "príncipes encantados", o que fez que mantivessem com eles, por um tempo, uma ligação de caráter fusional (Levy \& Gomes, 2008).

Nessas mães, o sofrimento vivenciado em cada relacionamento parecia nunca ser suficiente para "aprenderem com a experiência" e empreenderem uma busca mais adequada (Bion, 1962/1991). Repetiam, sem elaboração, as soluções pouquíssimo adequadas já anteriormente adotadas, envolvendo-se insistentemente com homens tão imaturos quanto elas e que muito pouco tinham a oferecer em termos de segurança e afeto. A dependência afetiva infantil dessas mães, evidenciada também no DFH, não lhes permitia escolhas objetais mais adequadas, levando-as a perpetuar seus conflitos intra e extrapsíquicos, dificultando, inclusive, a formação de vínculos saudáveis também com os filhos (Freud, 1914/1969).

Nos relatos das mães, pode-se identificar, ainda, a presença de aspectos masoquistas. Apesar do abandono e das agressões sofridas, elas continuavam a se envolver com homens que possuíam o mesmo perfil: pouco protetores e continentes com elas e com os filhos. Eva e Ana, como exemplos de casos extremos, permaneceram com parceiros violentos durante anos, colocando em risco, além de suas vidas, também a de seus filhos, evidenciando a força da pulsão de morte existente nelas. Pulsão de morte presente também no comportamento compulsivo alcoolismo - de Rosa e Dirce cuja repercussão era visível nos setores A-R e S-C, afetando enormemente sua autoestima.

A violência mostrou-se como um traço psicológico importante e ainda preocupante em Rosa e Eva, exigindo a intervenção de um superego externo, representado pelo Conselho Tutelar e pela escola. As mães, banalizando a agressividade com que tratavam os filhos, justificavam-na como um recurso necessário para educar e disciplinar os pequenos. Já Cibele, Berenice, Ana, Dirce e Maria negavam qualquer negligência infligida aos filhos, sem noção da gravidade de sua conduta.

A agressividade e a negligência evidenciadas nessas mães confirmam o que Klein e Rivière (1937, 1975) afirmam a respeito da rejeição que pode ocorrer entre mães e filhos. Dados encontrados nos protocolos do DFH, tais como agressividade, hostilidade e impulsividade, e também vistos nos relatos, colocam em evidência o predomínio do funcionamento do Id no comportamento dessas mães. Pouco comprometidas com seu papel materno, elas não exerciam suas funções maternas de prover, principalmente, afeto e proteção e nem de oferecer os cuidados básicos para uma sobrevivência digna e segura.

A má elaboração em Cibele, Rosa, Eva, Berenice, Maria e Ana das posições esquizoparanoide e depressiva, evidenciada pelo diagnóstico adaptativo que as inseriram no Quadro Grave (Simon, 1999; 2005), encaminhou-as, sob o predomínio da pulsão de morte, a todos os setores adaptativos, a adotar ações e condutas primitivas e pouquíssimo adequadas (Klein \& Rivière, 1937, 1975). No caso de Dirce, pertencente ao Quadro Mediano houve possibilidade de, quando sob o predomínio da pulsão de vida, como no caso da produtividade, adotar soluções mais adequadas; mas, nos demais setores, notadamente no setor $\mathrm{A}-\mathrm{R}$, submetido à pulsão de morte, notaram-se ações e condutas muito menos adequadas, como a falta de cuidados com os filhos e consigo mesma.

O alcoolismo e a dependência de drogas foram constatados, ainda, em todos os parceiros das mães estudadas. Esta escolha apontava para parceiros 
que não cuidariam delas e nem de seus filhos, e não ofereceriam suporte adequado como figuras paternas dadas a violência e indisponibilidade com elas e os filhos. Assim, tanto elas quanto os filhos ficaram à mercê do abandono e da violência desses parceiros/pais.

As mães estudadas mostraram-se presas a um modelo de papel materno determinado por padrões repetitivos que tiveram origem em relações objetais regredidas e imaturas.

Pode-se traçar uma relação dinâmica entre a negligência e violência sofrida por elas próprias na infância e a infligida aos filhos, revelando a repetição da violência, da agressividade e da negligência de cuidados à infância. Não conseguiram dar novo significado às relações com os filhos e repetiram de forma mais intensa os traumas vivenciados nas relações com os próprios pais, numa transmissão transgeracional (Berenstein, 1981; Freud, 1914,1969; Granjon, 2001).

Esses dados encontrados nas mães estudadas mostram similaridade com pesquisas nas quais as mães (e os pais) que sofreram abandono e violência na infância estão mais propensas à repetição da agressividade e do abandono na idade adulta com seus filhos. Esta repetição ficou evidenciada na relação com os filhos e no próprio acolhimento deles (Silva et al., 2009; Soejima \& Weber, 2008).

As relações objetais das mães com as figuras maternas mostraram-se comprometidas em todos os casos. Nota-se que essas relações interferiam na adequação do setor A-R, que estava permeado por fantasias inconscientes relacionadas à falta de amor das figuras maternas e comprometendo o desenvolvimento do próprio papel materno (De Felice, 2006), reproduzindo com os filhos aquilo que vivenciaram na própria infância, e de forma até mais acentuada.

Dessa forma, percebe-se na história de todas as mães, infantilidade e dependência afetiva que as impediram de desenvolver o estado necessário de proximidade afetiva com seus filhos para cuidar deles e protegê-los. Mostraram-se incapazes de se colocar-se em um estado de compreensão e empatia dos filhos, que possibilitasse suprir suas necessidades básicas e afetivas e que promovesse a sensação de amparo durante o desenvolvimento deles.

0 estado de reverie materna (Bion, 1991) falhou, com uma perturbação na sustentação da identificação projetiva dos filhos, assim como não apareceu nessas mães o desenvolvimento da preocupação materna primária (Winnicott, 1956, 2000), não podendo regredir de forma saudável, para a empatia e compreensão de seu bebê, porque elas não haviam evoluído adequadamente a fase adulta de desenvolvimento. Não puderam, ainda, ser o organizador psíquico de suas crianças, não tendo elas próprias um desenvolvimento mental saudável, e, portanto, não conseguiram auxiliar os filhos nesse aspecto.

As mães não conseguiram ser continentes, pois elas próprias estavam entregues a relações objetais pouco desenvolvidas e imaturas, e ao desejo de serem cuidadas e protegidas por seus parceiros, ou por figuras femininas significativas.

Todas as mães mostraram dificuldades em desenvolver vínculos positivos com seus filhos e cuidar deles adequadamente (Weber et al., 2002). Um exemplo disso é que, com exceção de Maria e Ana, cujos filhos haviam sido acolhidos no abrigo pela primeira vez, as demais mães já haviam passado pela experiência de um primeiro acolhimento com os filhos mais velhos. E nada fizeram para evitar um novo acolhimento.

Portanto, não é possível afirmar que um segundo acolhimento promovesse mudanças positivas no relacionamento com os filhos e que a negligência não fosse repetida sem uma intervenção psicológica preventiva que trabalhasse com a reinserção das crianças em suas casas e com o apoio dos cuidados básicos que as mães deveriam ter com eles, conforme Pereira e Costa (2005) e Rabault (2008).

Os parceiros de Cibele, Rosa, Ana e Dirce moravam com elas no momento do acolhimento, mas isso não foi suficiente para que fizessem algo para evitá-lo. Esse dado está de acordo com a pesquisa de Miguez-Naiff e Sá (2007) e de Soejima e Weber (2008), que mostraram uma realidade de mães solitárias, sem o apoio do parceiro, ou com parceiros transitórios que não contribuíam para o cuidado dos filhos ou seu sustento.

No setor da produtividade, as mães, com exceção de Dirce, apresentavam soluções pouco adequadas. Nos protocolos do DFH das mães, apareceram sentimentos de incapacidade e frustração que podem estar associados à baixa produtividade de grande parte das mães.

A dependência ou a imaturidade afetiva evidenciadas nos desenhos colaboraram para a manutenção deste quadro de dificuldades no setor Pr, pois evidenciou que não confiavam em si mesmas 
e esperavam do outro a satisfação de suas necessidades. Nas histórias, é possível perceber ainda a fragilidade egoica em todos os casos. Imaturas e despreparadas profissionalmente não se mostravam capazes de atender às necessidades dos filhos, negligenciando-os de forma persistente.

Essas mães não revelavam uma busca efetiva por mudanças neste setor, por um trabalho que pudesse auxiliá-las a ter melhores condições materiais para suprir as próprias necessidades materiais e a dos filhos. Nenhuma delas conseguia sustentar a si própria e nem aos filhos (Miguez-Naiff \& Sá, 2007; Soejima \& Weber, 2008). Elas até desenvolviam algumas ocupações, mas eram insuficientes para melhorar a adequação neste setor.

O mesmo não foi observado com Dirce. Mesmo tendo apresentado soluções pouquíssimo adequadas no setor $\mathrm{A}-\mathrm{R}$, estas não interferiram em sua adequação no setor Pr. Além de produzir, Dirce mantinha relações interpessoais positivas no seu local de trabalho e mostrou sentir-se responsável pelas necessidades básicas dos filhos apesar do acolhimento.

No setor sociocultural os "sentimentos, atitudes e ações" direcionados às instituições, valores e costumes de todas as mães foram considerados pouco adequados (Simon, 1989).

As mães, de um modo geral, mostraram-se isoladas, embora algumas tenham recebido benefícios assistenciais. Não houve a valorização de uma rede social de apoio que pudesse auxiliá-las nos cuidados básicos com os filhos e com a qual pudessem desenvolver valores sociais mais adequados (Guará, 2005).

Cibele, Rosa, Eva, Berenice e Ana estavam afastadas inclusive de suas famílias. Maria e Dirce moravam com as mães e tinham contato com seus irmãos, mas isso não configurou ações mais positivas relacionadas a sua postura como cidadãs.

As famílias, nestes casos, cobravam a inadequação dessas mães e em seus relatos ficou claro que gostariam de ter um comportamento mais adequado e aceito socialmente. Os sentimentos de inferioridade e insegurança, já expostos no setor A-R e configurados nos $\mathrm{DFH}$, podem estar associados a essas cobranças sociais.

As mães relataram que sentem-se desrespeitadas pelas intervenções externas realizadas em suas vidas por denúncia de familiares, conselheiros tutelares e assistentes sociais, aparentemente sem perceber que seus deveres como mães estavam comprometidos (Oliva, 2004). Assim, o abrigo é sentido como perseguidor, assim como o Conselho Tutelar através das intervenções realizadas (Minuchin, Colapinto \& Minuchin, 1999), como se essas instituições estivessem contra elas.

Em contrapartida, aceitaram o auxílio de instituições públicas que as informaram sobre os seus direitos sociais e as apoiaram na busca por eles, no recebimento de cestas básicas, reembolso bolsa família e refeições; ou no caso de Ana, com o próprio acolhimento, e de Berenice, que conseguiu o apoio jurídico para voltar para a casa do pai por seu direito à herança.

Ficou evidenciada, assim, uma ausência do funcionamento do Superego, denotando imaturidade até na conduta social, não se mostrando capazes de assumir um papel social adulto, pautado em direitos e deveres. Desconheciam seus direitos e desconsideravam seus deveres como a proteção e cuidados com os filhos, ou de respeito a regras sociais básicas.

A agressividade, hostilidade e impulsividade foram fatores psicológicos evidenciados nos desenhos das mães e revelados em suas histórias no setor A-R, no relacionamento com os filhos, parceiros e familiares, mas no setor $\mathrm{S}-\mathrm{C}$, em relação às instituições e à sociedade em geral, mostraram-se como uma forma de defesa contra a angústia e a ansiedade que essas relações provocavam.

As soluções no setor orgânico mostraram-se adequadas na maioria dos casos. Berenice e Maria mostraram soluções pouco adequadas e apenas Rosa mostrou soluções pouquíssimo adequadas. Todas as mães, com exceção de Berenice, revelaram aparência extremamente simples, e higiene pessoal preservada.

Cibele, Eva, Ana e Dirce mostraram "sentimentos e ações" mais positivos quanto à própria saúde, apresentando cuidados consigo mesmas (Simon, 1989). Um fator que contribuiu para este setor estar menos prejudicado pode ser o fato de que a figura do médico - diferentemente do psicólogo - é mais próxima e familiar a essa população através dos contatos mantidos nas Unidades Básicas de Saúde, geralmente localizadas em regiões próximas as suas casas, onde recebem as medicações distribuídas gratuitamente.

Em relação à gravidez, nenhuma delas mostrou qualquer cuidado preventivo. Sequer chegavam a pensar em planejamento familiar. Mostraram uma 
incapacidade de pensar sobre os filhos, como se não tivessem desenvolvido uma representação mental da função materna (Bion, 1991).

\section{Considerações finais}

0 acolhimento em abrigos é uma realidade preocupante no Brasil e em outros países do mundo pelo número de crianças e adolescentes institucionalizados. Dessa forma, pesquisar mães de crianças abrigadas revelou-nos nuances importantes sobre a parentalidade: mães que não apresentavam condições de exercer a maternidade de forma adequada e pais ausentes e imaturos.

Os instrumentos utilizados na pesquisa possibilitaram obter dados importantes sobre aspectos adaptativos e psicológicos, autoconceito e autoimagem das mães. Assim, a EDAO e o DFH contribuíram positivamente para a realização do estudo adaptativo e psicológico das 7 mães que foi se configurando, nas histórias, em características repetitivas que apareceram nas entrevistas e na avaliação dos desenhos.

Os fatores psicológicos evidenciados no DFH das mães mostraram autoconceito e autoimagem preponderantemente negativos revelando imaturidade, dependência afetiva, regressão e impulsividade, sentimentos de inferioridade e inadequação. Os fatores adaptativos revelados na EDAO evidenciaram adaptação ineficaz grave em três mães, adaptação ineficaz severa em três mães e adaptação ineficaz moderada em uma mãe. As soluções inadequadas apareceram principalmente nos setores adaptativos A-R, Pr e S-C. Constatamos, então, que os fatores psicológicos e adaptativos das mães apresentam-se fortemente associados ao abrigamento dos filhos.

Esse quadro grave mostrou que as soluções obtidas para suas dificuldades nestes setores foram repetitivas e pouco refletidas, dependência infantil, impulsividade com predomínio do funcionamento do Id, fragilidade egoica, assim como ausência de um funcionamento superegoico.

Todas as mães tinham tido seus filhos acolhidos por violência praticada por elas: agressividade ou negligência. No entanto, não assumiam sua responsabilidade nessa realidade de abandono e rejeição, o que limitava consideravelmente as mudanças necessárias e fundamentais nesse contexto.

Verifucamos que a pouca conscientização da própria violência estava associada à repetição psíquica do modelo de violência vivenciado na própria infância. Todas as mães haviam sido vítimas, como seus filhos, de negligência ou agressão por parte dos pais e reproduziam isso em seu papel parental.

A transmissão transgeracional da violência foi então revelada, pois não puderam modificar esses conteúdos traumáticos e elaborar as situações de dor e sofrimento, infligindo de maneira repetitiva e mais acentuada aos seus filhos sob forma de falta de proteção e de afeto. Essas mães foram pouco protegidas e cuidadas na infância e assumiram, quando adultas, uma postura ainda mais comprometida com suas crianças, pois apresentaram uma grande dificuldade em elaborar as experiências vivenciadas com suas famílias.

Assim, vínculos positivos e ternos com os filhos não foram estabelecidos, o que impedia o cuidado e a prevenção da violência intrafamiliar também em relação aos parceiros. Permitiam, desse modo, que a violência se repetisse com elas próprias novamente e com os filhos, unindo-se a parceiros imaturos e, muitas vezes, violentos e agressores.

A psicoterapia como medida de prevenção relacionada aos casos estudados seria importantíssima, tendo em vista a classificação diagnóstica adaptativa das mães. Sem intervenções adequadas, o vínculo das mães com seus filhos não apresentarão diferenças positivas significativas e é preciso considerar que estas mães necessitam de auxílio urgente para suas dificuldades psicológicas e sociais, caso contrário não haverá mudanças na qualidade da adaptação, mantendo-se a repetição psíquica. E a transmissão desses conteúdos torna-se uma grande preocupação, pois poderá perpetuar-se através dos filhos.

Precisamos, então, estar atentos às particularidades dessa demanda para oferecer socorro psicológico, que deve ocorrer em três momentos: antes da institucionalização da criança, durante o abrigamento e por meio de um acompanhamento psicológico e social quando a criança retorna para casa, procurando-se evitar que dificuldades existentes antes do abrigamento e que possam ter sido agravadas pelo distanciamento da institucionalização possam gerar novo abrigamento. 


\section{Referências}

Berenstein, I. (1981). Psicoanalisis de la estructura família: del destino a La significación. Barcelona: Paidos.

Bion, W. R. (1991). O aprender com a experiência. Rio de Janeiro: Imago. (Obra originalmente publicada em 1962).

Lei n. 8.069 de 13 de julho de 1990 (1990). Dispõe sobre o Estatuto da Criança e do Adolescente e dá outras providências. Brasília, DF. Recuperado em 3 set. 2013, de http://www.planalto.gov.br/ccivil_03/leis/18069.htm

De Felice, E. M. (2006). Vivências da maternidade: e suas consequências para o desenvolvimento psicológico do filho. São Paulo: Vetor.

Dixon, L., Browne, K., \& Hamilton-Giachritsis, C. (2009). Patterns of risk and protective factors in the intergenerational cycle of maltreatment. Journal of Family Violence, 24, 111-122.

Freud, S. (1969). Recordar, repetir e elaborar. In Edição standard brasileira das obras psicológicas completas de S. Freud. (Vol. 12). Rio de Janeiro: Imago. (Obra originalmente publicada em 1914).

Granjon, E. (2001). A elaboração do tempo genealógico no espaço do tratamento da terapia familiar psicanalítica. In O. B. R. Correa (Org.). Os avatares da transmissão psíquica geracional (pp. 16-43). São Paulo: Escuta.

Guará, I. M.F.R. (2005). Dilemmas and advances on Brazilian shelter's institutes. In

Children and Youth in Emerging and Transforming Societies. International Conference. Norway: University of Oslo. Recuperado em 30 maio 2010, de http://www.neca. org.br/wp-content/uploads/2010/07/dilemas-e-avancos-dos-abrigos-no-brasil.pdf

Klein, M., \& Rivière, J. (1975). Amor, ódio e reparação. São Paulo: Imago. (Obra originalmente publicada em 1937).

Leavell, H. R., \& Clark, E.G. (1965). Preventive medicine for the doctor in his community. An epidemiologic approach. Nova York: Mac Graw-Hill Book Company.

Levy, L., \& Gomes, I. C. (2008). Relação conjugal, violência psicológica e complementaridade fusional. Psicologia Clinica, 20(2), 163-172.
Machover, K. (1949). Proyección de la personalidad en el dibujo de la figura humana: un método de la investigación de la personalidad. La Habana: Cultural.

Miguez-Naiff, L., \& Sá, C. P. (2007). De mãe para filha, o legado da exclusão social: um estudo de memórias autobiográficas. Memorandum, 13, 88-99. Belo Horizonte: UFMG; Ribeirão Preto: USP. Recuperado em 01 dezembro 2009, de http://www.fafich.ufmg.br

Minuchin, P., Colapinto,J., \& Minuchin, S. (1999). Trabalhando com famílias pobres. Porto Alegre: Artmed.

Oliva, P. P. (2004). 0 desvendamento do real numa instituição de abrigo para crianças e adolescentes. Revista Virtual Textos \& Contextos, 3(1), 1-13. Recuperado em 10 janeiro 2010, de http://revistaseletronicas.pucrs. br

Pereira, J. M. F., \& Costa, L. F. (2005). Os desafios na garantia do direito à convivência

familiar. Revista Brasileira de Crescimento Desenvolvimento Humano, 15(1), 19-31. Recuperado em 10 janeiro 2010, de http://pepsic.bvsalud.org

Rabault, B. (2008). Expériences des Villes de l'Europe. In M. B. Zola (Org.). Cooperação

Internacional para proteção social de crianças e adolescentes: o direito à convivência familiar e comunitária. (pp. 293-295). São Bernardo do Campo: Fundação Criança de São Bernardo do Campo.

Silva, E. R. A. (Org.). (2004). O direito à convivência familiar e comunitária: os abrigos para crianças e adolescentes no Brasil. Brasília: IPEA/CONANDA. Recuperado em 10 fev. 2009, de http://www.ipea. gov.br $/ 082 / 08201004 . j s p ? t$ tCD_CHAVE $=2386$

Silva, M. A., Falbo Neto, G. H., \& Cabral Filho, J. E. (2009) Maus-tratos na infância de mulheres vítimas de violência. Psicologia em Estudo, Maringá, 14(1), 121-127.

Simon, R. (1989). Psicoterapia clínica preventiva. São Paulo: EPU.

Simon, R. (1995). Manejo de Angústia na Entrevista Preventiva. Boletim de Psicologia, 45(102), 53-57.

Simon, R. (1996). Proposta de redefinição da EDAO. Apresentado ao II Encontro de Técnicas de Exame Psicológico, Instituto de Psicologia da USP.

Simon, R. (1999). Concordâncias e divergências entre psicanálise e psicoterapia psicanalítica. Jornal de Psicanálise, 32(58/59), 245-264. 
Simon, R. (2005). Psicoterapia breve operacionalizada: teoria e técnica. São Paulo: Casa do Psicólogo.

Soejima, C.S., \& Weber, L.N.D. (2008). 0 que leva uma mãe a abandonar um filho? Aletheia, 28, 174-187.

Turato, E. R. (2008). Tratado da metodologia da pesquisa clínico-qualitativa: construção teórico-epistemológica, discussão comparada e aplicação nas áreas da saúde e humanas. Petrópolis: Vozes.

Van Kolck, O.L. (1984). Testes projetivos gráficos no diagnóstico psicológico. São Paulo: EPU.
Weber, L. N. D., Viezzer, A. P., Brandenburg, O. J., \& Zocche, C. R. E. (2002). Famílias que maltratam: uma tentativa de socialização pela violência. Psico-USF, 7, 163-173.

Winnicott, D. W. (2000). A preocupação materna primária. In Da pediatria à psicanálise: obras escolhidas. (pp. 399-405). Rio de Janeiro: Imago. (Obra originalmente publicada em 1956). 